\title{
Photosynthetic Performance in Improved 'KDML105' Rice (Oryza sativa L.) Lines Containing Drought and Salt Tolerance Genes under Drought and Salt Stress
}

\author{
Dechudom Pamuta ${ }^{1}$, Meechai Siangliw ${ }^{2}$, Jirawat Sanitchon ${ }^{3}$, Jarunjit Pengrat ${ }^{4}$, \\ Jonaliza L. Siangliw ${ }^{2}$, Theerayut Toojinda ${ }^{2}$ and Piyada Theerakulpisut ${ }^{1,5 *}$ \\ ${ }^{1}$ Department of Biology, Faculty of Science, Khon Kaen University, Khon Kaen, 40002, Thailand \\ ${ }^{2}$ National Center for Genetic Engineering and Biotechnology (BIOTEC), National Science and Technology \\ Development Agency (NSTDA), 113 Thailand Science Park, Paholyothin Road, Khlong Nueng, Khlong Luang, \\ Pathum Thani 12120, Thailand \\ ${ }^{3}$ Department of Agronomy, Faculty of Agriculture, Khon Kaen University, Khon Kaen, 40002, Thailand \\ ${ }^{4}$ Khon Kaen Rice Research Center, Khon Kaen, 40000, Thailand \\ ${ }^{5}$ Salt-tolerant Rice Research Group, Department of Biology, Faculty of Science, Khon Kean University, Khon \\ Kaen, 40002, Thailand
}

\begin{abstract}
Rice (Oryza sativa L.) 'KDML105' is the most popular aromatic rice originating in Thailand. This cultivar is highly susceptible to abiotic stresses, especially drought and salt stress during the seedling stage. The objective of this study was to investigate the photosynthetic performance in response to drought and salt stress of four improved breeding lines, specifically CSSL94 and

ARTICLE INFO

Article history:

Received: 7 February 2020

Accepted: 20 July 2020

Published: 27 November 2020

DOI: https://doi.org/10.47836/pjtas.43.4.17

E-mail addresses:

dechudom@yahoo.com (Dechudom Pamuta)

meechai@biotec.or.th (Meechai Siangliw)

jirawat@kku.ac.th (Jirawat Sanitchon) jaranjit@brrd.mail.go.th (Jarunjit Pengrat)

jonaliza.sia@biotec.or.th (Jonaliza L. Siangliw)

theerayut@biotec.or.th (Theerayut Toojinda)

piythe@kku.ac.th (Piyada Theerakulpisut)

*Corresponding author

CSSL103 (containing drought-tolerant quantitative trait loci: DT-QTLs) and RGD1 and RGD4 (containing a salt-tolerance gene, SKC1), with 'KDML105' (susceptible) and DH103 (tolerant to drought and salt stress) as the controls. Rice seedlings were grown for 21 days in hydroponic solutions and then exposed to salt stress $(150 \mathrm{mM}$ $\mathrm{NaCl})$ or drought stress (20\% PEG6000) for 10 days. The results indicated that when subjected to drought and salt stress, all rice lines/cultivar exhibited significant
\end{abstract}


reductions in net photosynthesis rate $\left(P_{\mathrm{N}}\right)$, stomatal conductance $\left(g_{\mathrm{s}}\right)$, transpiration rate $(E)$, the maximal quantum yield of PSII photochemistry $\left(F_{\mathrm{v}} / F_{\mathrm{m}}\right)$, the effective quantum yield of PSII photochemistry $\left(F_{\mathrm{v}}{ }^{\prime} / F_{\mathrm{m}}{ }^{\prime}\right)$, photosynthetic pigments, and SPAD readings, whereas water use efficiency (WUE) and non-photochemical quenching (NPQ) increased. Compared with 'KDML105', CSSL94, and CSSL103 were more tolerant to both drought and salinity, showing less reduction in all photosynthetic parameters. For RGD1 and RGD4, it was confirmed that these lines had a higher level of salt tolerance than 'KDML105' based on better photosynthetic performance under salt stress, demonstrating that these lines were also more tolerant to drought stress.

Keywords: Chlorophyll fluorescence, drought stress, photosynthetic performance, rice, salt stress

\section{INTRODUCTION}

Rice is the most important staple food crop for almost all countries in Asia including Thailand, and the demand for rice is ever-increasing with the growing global population (Lin et al., 2018). Rice production is associated with a whole range of influencing factors such as variety, terrain, climate, fertilization, and soil properties (Ran et al., 2018). Moreover, various types of stress, biotic, and abiotic, adversely affected the survival, growth, and performance of rice (Anami et al., 2020). Among abiotic stress factors, drought and salinity dramatically reduced the growth and yield of rice, particularly in rainfed ecosystems (Sekar \& Pal, 2012). In Thailand, approximately $76 \%$ of the total of 9.2 million ha of rice-growing areas are under rainfed conditions. The majority of the rainfed lowland areas are found in the northeast (4.8 million ha) and the north (1.4 million ha) regions. These areas are droughtprone, and rice yield is low and fluctuates between 1.5 and $2.2 \mathrm{t} \mathrm{ha}^{-1}$ (Jongdee et al., 2006). Recently, it was estimated that 55$68 \%$ yield loss occurred in two study areas in Northeast Thailand in the drought year of 2012 (Polthanee et al., 2014). Northeast Thailand is also affected by saline soils, where $18 \%$ of the agricultural land (1.84 million ha) is affected by salts to varying degrees (Arunin \& Pongwichian, 2015). A study involving a total of 51 farmers' fields in this region from 2002-2005 revealed an average of $20 \%$ reduction in rice yield even under slightly saline soils having the electrical conductivity of saturated soil extract $\left(\mathrm{EC}_{\mathrm{e}}\right)$ between 3 and $5 \mathrm{dS} \mathrm{m}^{-1}$ (Clermont-Dauphin et al., 2010).

Photosynthesis is the fundamental metabolic process determining crop growth and yield, but it is strongly inhibited by drought and salinity (Pandey \& Shukla, 2015). In rice, a strong positive relationship between photosynthesis capacity and vegetative growth (Murata, 1981) as well as grain yield (Ambavaram et al., 2014) has been reported. Therefore, more tolerant rice genotypes are better able to maintain a more efficient photosynthetic capacity 
under drought (Ambavaram et al., 2014) and salt stress (Li et al., 2017). Drought and salinity negatively influence photosynthetic performance through decreased stomatal conductance, transpiration rate, photosystem II efficacy, and photosynthetic pigments (Hungsaprug et al., 2019; Netondo et al., 2004). The photosynthetic rate is also adversely affected by limited $\mathrm{CO}_{2}$ diffusion into the chloroplast, via limitations on stomatal conductance and the mesophyll transport of $\mathrm{CO}_{2}$, as well as alterations in leaf photochemistry and carbon metabolism (Chaves et al., 2009). These effects vary according to the intensity, duration, and frequency of stress as well as the plant species (Rötzer et al., 2012). Photosystem II is the most susceptible component of the photosynthetic machinery that carries the brunt of abiotic stress (Gururani et al., 2015). Thus, abiotic stress usually leads to photoinhibition through damage to PSII reaction centers (Nishiyama et al., 2006).

'Khao Dawk Mali 105' or 'KDML105', known in the world market as 'Thai Hom Mali' or 'Thai jasmine rice', has a unique fragrance and good eating/cooking quality. 'KDML105' is mostly cultivated in northeast Thailand; hence, its growth and yield are under threats from both drought and salinity stress. 'KDML105' is susceptible to abiotic stresses, especially drought (Kanjoo et al., 2012) and salinity (Kanawapee et al., 2012). Efforts have been made to improve rice cultivars to obtain better resistance to salinity and water deficit stresses through molecular marker-assisted backcross breeding (MABC). Several rice lines were developed as donors for droughttolerance quantitative trait loci (DT-QTL), including DH103 and DH212 (Lanceras et al., 2004). Subsequently, through MABC, 90 chromosome segment substitution lines (CSSLs) with a 'KDML105' genetic background (CSSL no. 1-90) were developed, which carried DT-QTL from chromosomes 1, 3, 4 and 9 of DH212and chromosome 8 of DH103 (Kanjoo, 2011). These CSSLs lines were evaluated for agronomic traits in a field condition under drought stress compared with 'KDML105', and it was found that these improved lines showed higher grain yield than 'KDML105' (Kanjoo et al., 2012). Two selected CSSL lines (CSSL1 and CSSL4), which carried DT-QTL from chromosome 1 of DH212, were evaluated for physiological responses under drought stress. Only CSSL4 revealed superior tolerance over 'KDML105' through its ability to maintain stable net photosynthesis rates (Hungsaprug et al., 2019). However, detailed physiological drought responses of other CSSL lines introgressed with DT-QTL from other chromosomes have not been evaluated.

To improve the salt tolerance of rice, the SKC1 gene controlling salt tolerance in rice has been identified (Gregorio et al., 2002). The SKC1 gene functions in controlling ion homeostasis by increasing $\mathrm{K}^{+}$content and lowering $\mathrm{Na}^{+} / \mathrm{K}^{+}$in rice shoots, thereby increasing yields under salinity stress (Ren et al., 2005; Thomson et al., 2010). Introgression lines with the 'KDML105' rice 
genetic background carrying QTL and SKC1

for salt tolerance were derived by crossing 'KDML105' with salt-tolerant FL496 (IR66946-3R-196-1-1) or FL530 (IR664963R-230-1-1). These backcross introgression lines of 'KDML105' were proven to have higher salt tolerance than 'KDML105', as indicated by lower shoot $\mathrm{Na}^{+} / \mathrm{K}^{+}$and higher yield under salt stress (Punyawaew et al., 2016; Vanavichit et al., 2018). However, detailed studies on the effects of drought and salt stress on physiological responses of these improved lines have not been reported. These studies are expected to provide an insight into how physiological and biochemical mechanisms are differentially enhanced by the introgressed genes, which enable higher tolerance of the improved lines compared with the sensitive parent 'KDML105'.

Photosynthetic performance under stress is one of the most important processes determining stress tolerance ability, growth, and yield. In this study, we evaluated the photosynthetic performance under drought and salt stress of four improved lines with a 'KDML105' genetic background introgressed with DT-QTL (from chromosome 8 of DH103) or the SKC1 gene. Various photosynthetic parameters, including net photosynthesis rate, chlorophyll fluorescence, and leaf greenness index, were analyzed to clarify the drought- and salt-tolerance mechanisms. The information provided in this study may be applied for selecting appropriate introgression lines for breeding rice cultivars with tolerance to both drought and salt stresses.

\section{MATERIALS AND METHODS}

\section{Plant Materials and Growth Condition}

Six (6) rice lines/cultivars were used in this study, including CSSL94 and CSSL103, which are CSSLs with a 'KDML105' genetic background carrying DT-QTL on chromosome 8; RGD14376 (RGD1) and RGD12150-B-21-MS3 (RGD4), which are backcross introgression lines of 'KDML105' carrying a salt tolerance gene (SKC1) on chromosome 1; 'KDML105', the original parental cultivar, which is susceptible to drought and salt stress; and the double-haploid line, DH103, which is known to be tolerant to both drought and salt stress (Lanceras et al., 2004; Nounjan et al., 2016). Seeds were kindly provided by the Rice Gene Discovery Unit, BIOTEC, Thailand. The experiment was conducted in the greenhouse at the Crop Station, Faculty of Agriculture, Khon Kaen University, Thailand. Seeds were soaked in $3 \%$ calcium hypochlorite for $30 \mathrm{~min}$ and then washed several times with distilled water. Seeds were then germinated in distilled water on filter paper in the dark at room temperature. After 3 days, germinated seeds were transferred to a plastic net placed over 15 L of Yoshida nutrient solution (Yoshida et al., 1976) in a plastic container $(50 \times 60 \times 11 \mathrm{~cm})$. In each container, 20 
germinated seeds per line/cultivar were randomly arranged and allowed to grow for 21 days, during which the nutrient solution was replaced every 4 days. On day 21 , the plants were separated into 3 treatment groups i.e. control, drought stress, and salt stress. For drought stress, plants were treated with Yoshida solution containing 20\% polyethylene glycol 6000 (PEG6000). For salt stress, plants were fed with Yoshida solution containing $150 \mathrm{mM} \mathrm{NaCl}$. For the control, plants continued to be fed with the Yoshida solution. The physiological traits were determined at 10 days after drought and salt treatments. The chosen concentration of PEG6000 had an osmotic potential of $-0.7 \mathrm{MPa}$, corresponding to moderate water stress (Osmolovskaya et al., 2018). The $150 \mathrm{mM} \mathrm{NaCl}$ solution had the same osmotic potential as the $20 \%$ PEG6000 solution; therefore, it imposes a similar level of osmotic stress. The $\mathrm{NaCl}$ solution had an approximate EC value of $14.8 \mathrm{dS} \mathrm{m}^{-1}$.

\section{Determination of Leaf Gas Exchange Parameters}

Net photosynthesis rate $\left(P_{\mathrm{N}}\right)$, stomatal conductance $\left(g_{\mathrm{s}}\right)$, transpiration rate $(E)$ and water use efficiency (WUE) were evaluated on the youngest fully expanded leaf of a randomly selected rice plant in each replicate by using a portable infrared gas exchange analyzer (LI-6400, LI-COR, NE, USA) from 9.00 to 11.00 a.m. The net photosynthesis rate was determined under the following conditions: $30^{\circ} \mathrm{C}, \mathrm{CO}_{2}$ concentration at $400 \mathrm{ppm}$, and $30-70 \%$ relative humidity. The photosynthesis photon flux density was maintained at 1500 $\mu \mathrm{mol}$ (photon) $\mathrm{m}^{-2} \mathrm{~s}^{-1}$.

\section{Measurement of Chlorophyll Fluorescence Parameters}

As soon as the above gas exchange measurement was completed, the photosynthetic efficiency of PSII was measured on the same leaf using a chlorophyll fluorometer (Hansatech, Kings Lynn, UK). The maximal quantum yield of PSII efficiency $\left(F_{\mathrm{v}} / F_{\mathrm{m}}\right)$ was calculated from minimal fluorescence in the dark-adapted state $\left(F_{0}\right)$ and maximal fluorescence in the dark-adapted state $\left(F_{\mathrm{m}}\right)$, as described by Schreiber (2004). Steady-state fluorescence in the light-adapted state $\left(F_{\mathrm{s}}\right)$ and maximal fluorescence in the light-adapted state $\left(F_{\mathrm{m}}{ }^{\prime}\right)$ were determined in the light condition. The effective quantum yield of PSII efficiency $\left(F_{\mathrm{v}}{ }^{\prime} / F_{\mathrm{m}}{ }^{\prime}\right)$ was calculated as described by Schreiber (2004). Non-photochemical quenching (NPQ) was computed as described by Bilger and Bjorkman (1990).

\section{Measurement of Leaf Greenness}

Leaf greenness of the same youngest fully expanded leaf used for gas exchange and chlorophyll fluorescence measurements was measured at 3 positions along the leaf blade from 9.00 to 11.00 a.m. using a SPAD-502 chlorophyll meter (Minolta Corp., Ramsey, New Jersey, U.S.A.). 
Dechudom Pamuta, Meechai Siangliw, Jirawat Sanitchon, Jarunjit Pengrat, Jonaliza L. Siangliw,

Theerayut Toojinda and Piyada Theerakulpisut

Determination of Photosynthetic

\section{Pigments}

Chlorophyll and carotenoid contents were determined by a modified method, as outlined by Arnon (1949) and Lichtenthaler (1987), using $0.1 \mathrm{~g}$ of leaf tissue. The absorbance of the pigment extract was estimated at 470,645, and $663 \mathrm{~nm}$ by using a spectrophotometer (Hanon, Model i3, China) with $80 \%$ acetone as a blank. The content of pigments was expressed as $\mathrm{mg} \mathrm{g}^{-1}$ tissue fresh weight. The pigment contents were calculated using the following equations:

Total chlorophyll $(\mathrm{TC})=\left[20.2 \mathrm{~A}_{645}+\right.$ $\left.8.02 \mathrm{~A}_{663}\right] \times[\mathrm{V} /(1000 \times \mathrm{W})]$

Chlorophyll $a(\mathrm{Chl} a)=\left[12.7 \mathrm{~A}_{663}-2.69\right.$ $\left.\mathrm{A}_{645}\right] \times[\mathrm{V} /(1000 \times \mathrm{W})]$

Chlorophyll $b(\mathrm{Chl} b)=\left[22.9 \mathrm{~A}_{645}-4.68\right.$ $\left.\mathrm{A}_{663}\right] \times[\mathrm{V} /(1000 \times \mathrm{W})]$

Carotenoid $(\mathrm{CA})=\left[1000 \mathrm{~A}_{470}-(1.82 \times\right.$ Chl $a)-(85.02 \times \mathrm{Chl} b)]$

where: $\mathrm{V}=$ total volume of extract $(\mathrm{ml})$; $\mathrm{W}=$ leaf weight $(\mathrm{g})$

\section{Experimental Design and Statistical Analysis}

The experiment was laid out as $3 \times 6$ factorials with a completely randomized design with four replications. The data were subjected to analysis of variance. Duncan's multiple range test (DMRT) was used to compare means at a significant difference of $p \leq 0.05$ and paired-samples t-test was performed at a significant difference of $p \leq 0.05$ and 0.01 . Pearson's correlation was calculated for the relationships among photosynthesis traits under drought and salt stress conditions. All calculations and data analyses were performed using SPSS for Windows version 19. In addition, cluster analysis based on fourteen physiological parameters was analyzed using PC-ORD version 5.10.

\section{RESULTS}

\section{Changes in Leaf Gas Exchange Parameters}

Drought generally imposed stronger inhibitory effects on leaf gas exchange parameters than salt stress. Under nonstressed control conditions, RGD4 showed the highest $P_{\mathrm{N}}\left(25.87 \mu \mathrm{mol} \mathrm{CO} \mathrm{CO}^{-2} \mathrm{~s}^{-1}\right)$, whereas DH103 showed the lowest $P_{\mathrm{N}}$ (19.26 $\left.\mu \mathrm{mol} \mathrm{CO} \mathrm{Cm}^{-2} \mathrm{~s}^{-1}\right)$. All improved lines (CSSL94, CSSL103, RGD1, and RGD4) and 'KDML105' showed significantly higher $P_{\mathrm{N}}$ than DH103 (Figure 1A). In contrast, under drought stress, DH103 showed the highest $P_{\mathrm{N}}\left(5.43 \mu \mathrm{mol} \mathrm{CO} \mathrm{CO}^{-2} \mathrm{~s}^{-1} ; 71.8 \%\right.$ reduction when compared with control plants), whereas 'KDML105' showed the lowest $P_{\mathrm{N}}\left(3.97 \mathrm{CO}_{2} \mathrm{~m}^{-2} \mathrm{~s}^{-1} ; 83.05 \%\right.$ reduction when compared with control plants) (Figure 1A). For the improved lines, $P_{\mathrm{N}}$ under drought stress decreased by 79.7, 79.8, 78.8, and $79.2 \%$ for CSSL94, CSSL103, RGD1, and RGD4, respectively, when compared with control plants. Under salt stress, RGD4 showed the highest $P_{\mathrm{N}}\left(12.82 \mu \mathrm{mol} \mathrm{CO} \mathrm{Cm}^{-2}\right.$ $\left.\mathrm{s}^{-1}\right)$, while 'KDML105' showed the lowest $P_{\mathrm{N}}\left(7.89 \mu \mathrm{mol} \mathrm{CO} \mathrm{CO}^{-2} \mathrm{~s}^{-1}\right)$ (Figure 1A). This suggested that RGD4 had higher salt tolerance compared to CSSL94, CSSL103, RGD1, and DH103. A similar trend was 

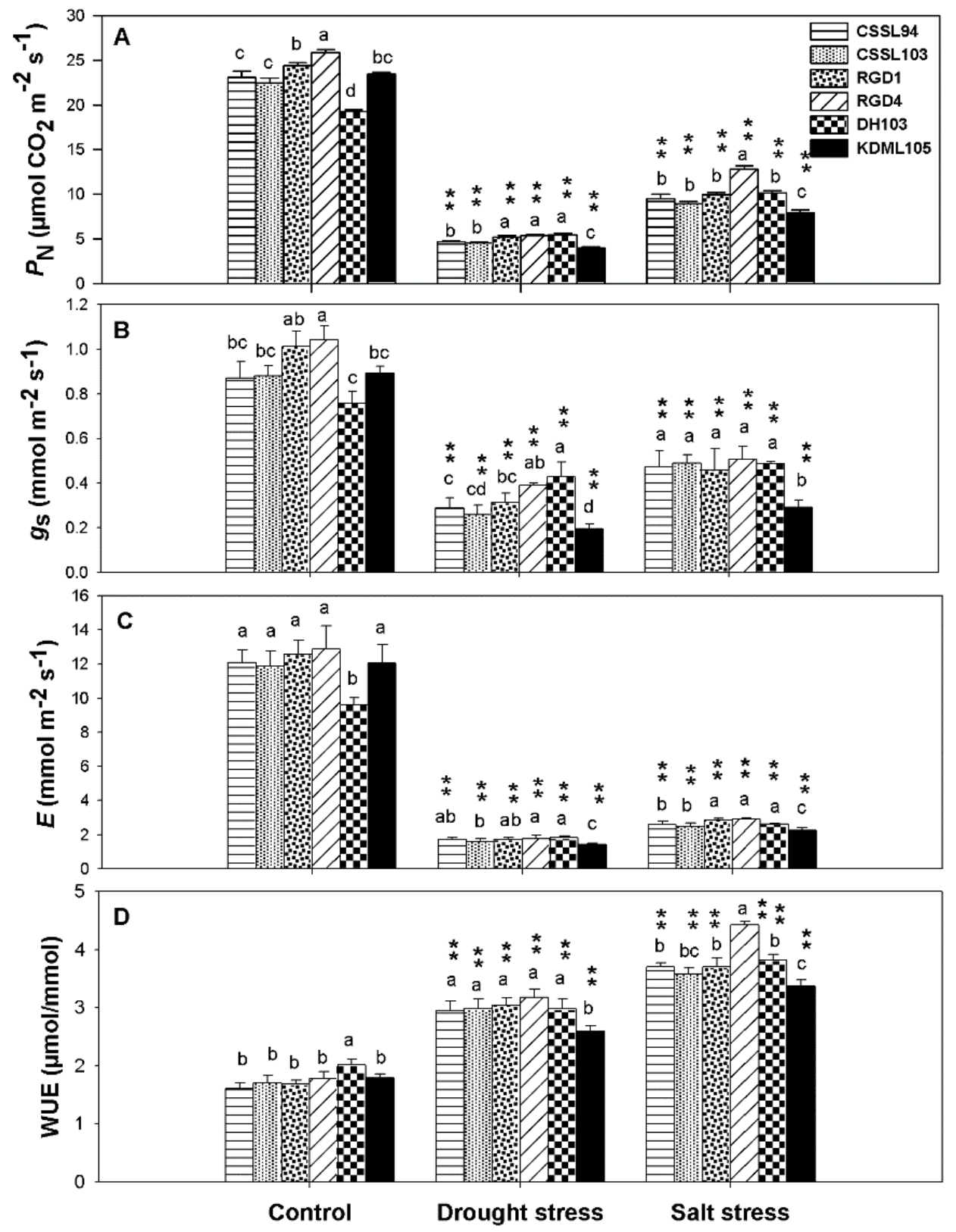

Figure 1. (A) Net photosynthesis rate $\left(P_{\mathrm{N}}\right),(\mathrm{B})$ stomatal conductance $\left(g_{\mathrm{s}}\right),(\mathrm{C})$ transpiration rate $(\mathrm{E})$, and (D) water use efficiency (WUE) under control, salt, and drought stress for 10 days. Bars with different letters within each treatment group are significantly different according to DMRT $(p \leq 0.05)$. The asterisk $(*, * *)$ indicates a significant difference $(p \leq 0.05$ and $p \leq 0.01)$ in the mean values between control and stress (drought or salt stress) conditions of each line/cultivar 
found in $g_{\mathrm{s}}$ (Figure 1B) and $E$ (Figure 1C). variance showed that $P_{\mathrm{N}}, g_{\mathrm{s}}, E$, and WUE Conversely, drought, and salt stress led to a were significantly affected by treatments large and significant increase in WUE in all $(\mathrm{T})$, lines/cultivar $(\mathrm{C})$, and treatments and rice lines/cultivars, particularly in RGD4 lines/cultivar interaction $(\mathrm{T} \times \mathrm{C})$, as shown under salt stress (Figure 1D). Analysis of in Table 1.

\section{Table 1}

Analysis of variance of studied parameters in six lines/cultivars of rice seedlings treated with drought treatment (20\% PEG6000) and salt treatment $(150 \mathrm{mM} \mathrm{NaCl})$

\begin{tabular}{llll}
\hline Parameter & $\begin{array}{l}\text { Lines/Cultivars }(\mathrm{C}) \\
(d f=5)\end{array}$ & $\begin{array}{l}\text { Treatment }(\mathrm{T}) \\
(d f=2)\end{array}$ & $\begin{array}{l}\text { Lines/Cultivars } \times \\
\text { Treatment }(\mathrm{C} \times \mathrm{T}) \\
(d f=10)\end{array}$ \\
\hline$P_{\mathrm{N}}$ & $16.99^{* *}$ & $2133.05^{* *}$ & $7.97^{* *}$ \\
$g_{\mathrm{s}}$ & $0.05^{* *}$ & $2.53^{* *}$ & $0.03^{* *}$ \\
$\mathrm{E}$ & $2.56^{*}$ & $782.65^{* *}$ & $2.51^{* *}$ \\
$\mathrm{WUE}$ & $0.3^{*}$ & $24.70^{* *}$ & $0.148^{*}$ \\
$F_{0}$ & $128.39^{* *}$ & $3376.042^{* *}$ & $119.45^{* *}$ \\
$F_{\mathrm{m}}$ & $221836.55^{* *}$ & $77857.62^{* *}$ & $13945.70^{* *}$ \\
$F_{\mathrm{v}} / F \mathrm{~m}$ & $0.0001^{* *}$ & $0.03^{* *}$ & $0.00002 \mathrm{~ns}$ \\
$F_{\mathrm{v}}{ }^{\prime} / F_{\mathrm{m}}{ }^{\prime}$ & $0.12^{* *}$ & $0.006^{* *}$ & $0.01 \mathrm{~ns}$ \\
$\mathrm{NPQ}$ & $0.052^{* *}$ & $0.055^{* *}$ & $0.005^{* *}$ \\
$\mathrm{SPAD}$ & $51.61^{* *}$ & $24.23^{* *}$ & $7.06^{* *}$ \\
$\mathrm{TC}$ & $0.339^{* *}$ & $1.666^{* *}$ & $0.129 * *$ \\
$\mathrm{Chl} a$ & $0.167^{* *}$ & $0.637^{* *}$ & $0.032^{* *}$ \\
$\mathrm{Chl} b$ & $0.167^{* *}$ & $0.637^{* *}$ & $0.07^{* *}$ \\
$\mathrm{CA}$ & $0.032^{* *}$ & $0.268^{* *}$ & $0.15^{* *}$ \\
\hline
\end{tabular}

Note. ${ }^{*}$ and $* *$ are means with significant differences at $p \leq 0.05$ and $p \leq 0.01$, respectively ns are means with no significant differences

\section{Changes in Chlorophyll Fluorescence Parameters}

Under drought stress, $F_{0}$ significantly increased in all lines/cultivar (except DH103) when compared to control plants. Of the lines/cultivar, 'KDML105' showed the highest $F_{0}$ whereas DH103 had the lowest, and all four improved lines had intermediate values. Under salt stress, 'KDML105' also showed the highest $F_{0}$, which was significantly higher than all other lines (Figure 2A). For $F_{\mathrm{m}}$, only RGD1, RGD4, and 'KDML105' showed a significant reduction under drought stress; 

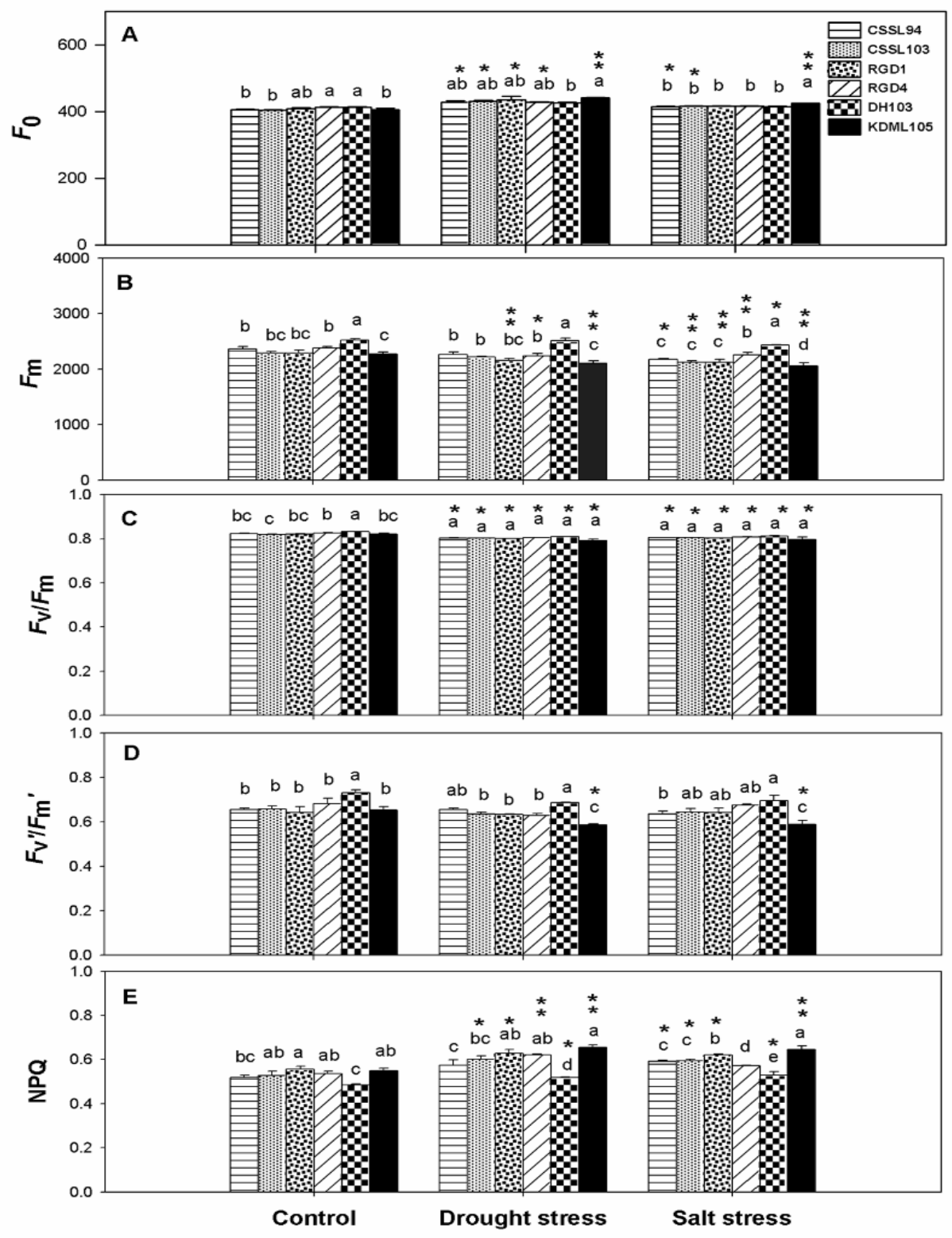

Figure 2. (A) Minimal fluorescence in the dark-adapted conditions $\left(F_{0}\right)$, (B) maximal fluorescence in the dark-adapted conditions $\left(F_{\mathrm{m}}\right),(\mathrm{C})$ maximum quantum yield of PSII efficiency $\left(F_{\mathrm{v}} / F_{\mathrm{m}}\right)$, (D) effective quantum yield of PSII efficiency $\left(F_{\mathrm{v}}{ }^{\prime} / F_{\mathrm{m}}{ }^{\prime}\right)$, and (E) non-photochemical quenching (NPQ) under control, salt and drought stress for 10 days. Bars with different letters within each treatment group are significantly different according to DMRT $(p \leq 0.05)$. The asterisk $(*, * *)$ indicates a significant difference $(p \leq 0.05$ and $p \leq 0.01)$ in the mean values between control and stress (drought or salt stress) conditions of each line/cultivar 
however, under salt stress, all six lines/ cultivar showed a significant reduction in $F_{\mathrm{m}}$ (Figure 2B). Both drought and salt stress resulted in significant reductions ( $p \leq$ $0.05)$ in $F_{\mathrm{v}} / F_{\mathrm{m}}$ of all rice lines/cultivar, with 'KDML105' showing the highest percent reduction (Figure 2C). However, for $F_{\mathrm{v}}{ }^{\prime}$ $F_{\mathrm{m}}$ ', only 'KDML105' showed a significant reduction $(p \leq 0.05)$ when exposed to both stress conditions (Figure 2D). Under both types of stress, compared with the controls, NPQ increased in all genotypes, with 'KDML105' showing the highest percent increase (Figure 2E). Furthermore, all improved lines (CSSL94, CSSL103, RGD1, and RGD4) showed higher $F_{\mathrm{v}} / F_{\mathrm{m}}$, $F_{\mathrm{v}}{ }^{\prime} / F_{\mathrm{m}}{ }^{\prime}$, and $F_{\mathrm{m}}$, and lower $F_{0}$ and NPQ under drought and salt stress than 'KDML105' (Figures 2A-2D). Analysis of variance showed that differences among lines/cultivar (C), treatments (T) and treatments and lines/ cultivar interaction $(\mathrm{T} \times \mathrm{C})$ were significant for $F_{0}, F_{\mathrm{m}}, F_{\mathrm{v}} / F_{\mathrm{m}}$, and $F_{\mathrm{v}}{ }^{\prime} / F_{\mathrm{m}}{ }^{\prime}$, except for $F_{\mathrm{v}} / F_{\mathrm{m}}$ and $F_{\mathrm{v}}{ }^{\prime} / F_{\mathrm{m}}{ }^{\prime}$, which did not show a significant difference in (T x C) (Table 1).

\section{Changes in the Content of Photosynthetic Pigments}

In general, drought had stronger effects on pigment concentrations than salt stress. Under drought stress, a significant reduction in TC was observed in CSSL94 (14.0\%), CSSL103 (9.6\%), RGD1 (19.5\%), RGD4 (20.6\%), and 'KDML105' (33.6\%) when compared with control plants (Figure 3C). The tolerant line DH103 exhibited stable TC, Chl $a$, and Chl $b$ contents under both types of stress (Figures 3A, 3B, and 3C). Under salt stress, only 'KDML105' showed significant reductions in TC (19.6\%), Chl $a(12.8 \%)$, and Chl $b$ (34.3\%), where the only exception was CSSL103, which showed a significant reduction in $\mathrm{Chl} b$ content (18.3\%). Under drought stress, all four improved introgression lines had significantly higher contents of TC, Chl $a$, and Chl $b$ than 'KDML105'. Under salt stress, only RGD1 and RGD4 had significantly higher TC, Chl $a$, and Chl $b$ contents than 'KDML105'. RGD4 had the highest pigment contents under salt stress (Figures 3A, 3B, and 3C). When subjected to drought stress, compared with the controls, carotenoid contents were significantly reduced in all lines/ cultivar, with 'KDML105' being the most reduced (27.6\%). However, under salt stress, carotenoid contents were significantly reduced in CSSL94, CSSL103, RGD1, and 'KDML105', but remained unchanged for RGD4 and DH103 (Figure 3D). RGD4 again had the highest carotenoid content under salt stress. For SPAD readings, under non-stressed conditions, DH103 showed the highest SPAD reading (37.08), whereas CSSL94, CSSL103, RGD1, RGD4 and 'KDML105' showed SPAD readings of 34.38, 33.68, 33.55, 35.20, and 34.40, respectively (Figure 3E). When subjected to drought and salt stress, leaf greenness of 'KDML105' was the most adversely affected among the six lines/cultivar. The percentage of reduction in SPAD readings under drought stress was 5.5, 1.6, 5.6, 7.0, and $15.3 \%$ in CSSL94, CSSL103, RGD1, RGD4, and 'KDML105', respectively, compared to the controls. Under salt stress, 
only KDML105 showed a significant reduction $(p \leq 0.01)$ in SPAD readings (decreased $9.85 \%$ compared to control), as shown in Figure 3E. Analysis of variance showed that differences among lines/cultivar (C), treatments $(\mathrm{T})$, and treatments and lines/ cultivar interaction $(\mathrm{T} \times \mathrm{C})$ were significant for all pigment parameters (Table 1).
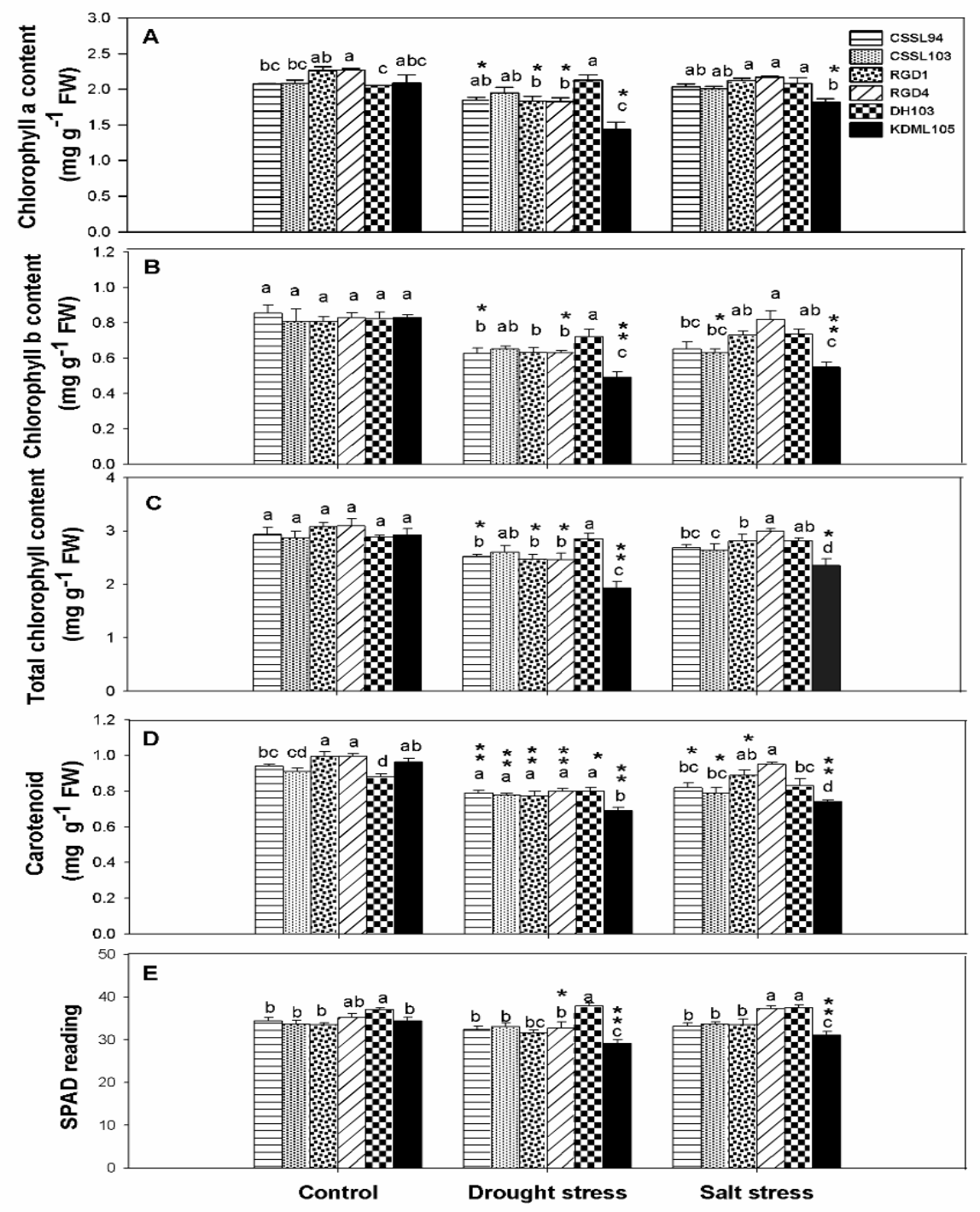

Figure 3. (A) Chlorophyll $a$, (B) chlorophyll $b$, (C) total chlorophyll, (D) carotenoid, and (E) SPAD readings under control, salt, and drought stress for 10 days. Bars with different letters within each treatment group are significantly different according to DMRT $(p \leq 0.05)$. The asterisk $(*, * *)$ indicates a significant difference ( $p \leq 0.05$ and $p \leq 0.01$ ) in the mean values between control and stress (drought or salt stress) conditions of each line/cultivar 


\section{The Correlation among Photosynthetic} Traits

Relationships among fourteen photosynthetic traits $\left(P_{\mathrm{N}}, g_{\mathrm{s}}, E\right.$, WUE, $F_{0}, F_{\mathrm{m}}, F_{\mathrm{v}} / F_{\mathrm{m}}, F_{\mathrm{v}}{ }^{\prime} / \mathrm{F}_{\mathrm{m}}{ }^{\prime}$, NPQ, SPAD, TC, Chl $a$, Chl $b$, and CA) under stress conditions were determined using Pearson's correlation analysis. Under drought stress (Table 2), highly significant $(p \leq 0.01)$ positive correlations were found between $P_{\mathrm{N}}$ and other leaf gas exchange parameters ( $\mathrm{g}_{\mathrm{s}}, E$, and WUE). Furthermore, highly significant $(p \leq 0.01)$ positive correlations were exhibited between $P_{\mathrm{N}}$ and fluorescence parameters $\left(\mathrm{F}_{\mathrm{m}}, F_{\mathrm{v}} / F_{\mathrm{m}}\right.$, and $\left.F_{\mathrm{v}}{ }^{\prime} / F_{\mathrm{m}}{ }^{\prime}\right)$ and between $P_{\mathrm{N}}$ and pigment parameters (SPAD, TC, Chl $a$, and $\mathrm{Chl} b$ ). In contrast, significant negative correlations were observed between $P_{\mathrm{N}}$ and $F_{0}(p \leq 0.05)$ as well as NPQ $(p \leq 0.01)$. Similarly, under salt stress (Table 3 ), significant positive correlations were found between $P_{\mathrm{N}}$ and $g_{\mathrm{s}}$, $E$, WUE, $F_{\mathrm{m}}, F_{\mathrm{v}} / F_{\mathrm{m}}, \mathrm{SPAD}, \mathrm{TC}, \mathrm{Chl} a, \mathrm{Chl}$ $b$, and CA (all traits; $p \leq 0.01$, except for $F_{\mathrm{v}} /$ $F_{\mathrm{m}}$, and CA; $\left.p \leq 0.05\right)$. In contrast, negative correlations were observed between $P_{\mathrm{N}}$ and $F_{0}(p \leq 0.01)$ as well as NPQ.

Table 2

Pearson's correlation coefficients ( $r$ values) among physiological parameters in rice seedling exposed to drought stress (20\% PEG6000)

\begin{tabular}{llllllll}
\hline Parameter & $P_{\mathrm{N}}$ & $g_{\mathrm{s}}$ & $\mathrm{E}$ & $\mathrm{WUE}$ & $F_{0}$ & $F_{\mathrm{m}}$ & $F_{\mathrm{v}} / F_{\mathrm{m}}$ \\
\hline$P_{\mathrm{N}}$ & 1 & & & & & & \\
$g_{\mathrm{s}}$ & $0.787^{* *}$ & 1 & & & & & \\
$\mathrm{E}$ & $0.730^{* *}$ & $0.687^{* *}$ & 1 & & & & \\
$\mathrm{WUE}$ & $0.715^{* *}$ & $0.488^{*}$ & $0.534^{* *}$ & 1 & & & \\
$F_{0}$ & $-0.444^{*}$ & $-0.482^{*}$ & -0.381 & $-0.645^{* *}$ & 1 & & \\
$F_{\mathrm{m}}$ & $0.541^{* *}$ & $0.610^{* *}$ & $0.536^{* *}$ & 0.284 & $-0.422^{*}$ & 1 & \\
$F \mathrm{~V} / F \mathrm{~m}$ & $0.521^{* *}$ & 0.366 & $0.680^{* *}$ & $0.534^{* *}$ & $-0.423^{*}$ & $0.553^{* *}$ & 1 \\
$F_{\mathrm{v}}{ }^{\prime} / F_{\mathrm{m}}{ }^{\prime}$ & $0.542^{* *}$ & $0.585^{* *}$ & $0.764^{* *}$ & $0.408^{*}$ & $-0.564^{* *}$ & $0.602^{* *}$ & $0.594^{* *}$ \\
$\mathrm{NPQ}$ & $-0.458^{* *}$ & $-0.565^{* *}$ & $-0.569^{* *}$ & -0.245 & $0.509^{* *}$ & $-0.840^{* *}$ & $-0.600^{* *}$ \\
$\mathrm{SPAD}$ & $0.571^{* *}$ & $0.671^{* *}$ & $0.567^{* *}$ & $0.413^{*}$ & $-0.464^{*}$ & $0.743^{* *}$ & 0.395 \\
$\mathrm{TC}$ & $0.620^{* *}$ & $0.556^{* *}$ & $0.505^{* *}$ & $0.414^{*}$ & $-0.416^{*}$ & $0.617^{* *}$ & $0.506^{*}$ \\
$\mathrm{Ch} 1 a$ & $0.549^{* *}$ & $0.527^{* *}$ & $0.427^{*}$ & 0.368 & $-0.441^{*}$ & $0.557^{* *}$ & $0.443^{*}$ \\
$\mathrm{Ch} l b$ & $0.641^{* *}$ & $0.461^{*}$ & $0.589^{* *}$ & $0.424^{*}$ & -0.196 & $0.602^{* *}$ & $0.539^{* *}$ \\
$\mathrm{CA}$ & -0.172 & 0.018 & -0.122 & $0.539^{* *}$ & 0.056 & 0.111 & -0.245 \\
\hline
\end{tabular}


Table 2 (Continued)

\begin{tabular}{|c|c|c|c|c|c|c|c|}
\hline Parameter & $F_{\mathrm{v}}^{\prime} / \mathrm{F}_{\mathrm{m}}{ }^{\prime}$ & NPQ & SPAD & $\mathrm{TC}$ & Chl $a$ & Chl $b$ & $\mathrm{CA}$ \\
\hline \multicolumn{8}{|l|}{$P_{\mathrm{N}}$} \\
\hline \multicolumn{8}{|l|}{$g_{\mathrm{s}}$} \\
\hline \multicolumn{8}{|l|}{$\mathrm{E}$} \\
\hline \multicolumn{8}{|l|}{ WUE } \\
\hline \multicolumn{8}{|l|}{$F_{0}$} \\
\hline \multicolumn{8}{|l|}{$F_{\mathrm{m}}$} \\
\hline \multicolumn{8}{|l|}{$F_{\mathrm{V}} / F \mathrm{~m}$} \\
\hline$F_{\mathrm{v}}{ }^{\prime} / F_{\mathrm{m}}{ }^{\prime}$ & 1 & & & & & & \\
\hline NPQ & $-0.745^{* *}$ & 1 & & & & & \\
\hline SPAD & $0.686^{* *}$ & $-0.758^{* *}$ & 1 & & & & \\
\hline $\mathrm{TC}$ & $0.647^{* *}$ & $-0.501^{*}$ & $0.555^{* *}$ & 1 & & & \\
\hline Chl $a$ & $0.600^{* *}$ & $-0.451^{*}$ & $0.518^{* *}$ & $0.978^{* *}$ & 1 & & \\
\hline Chl $b$ & $0.583^{* *}$ & $-0.495^{*}$ & $0.491^{*}$ & $0.733^{* * *}$ & $0.575^{* *}$ & 1 & \\
\hline $\mathrm{CA}$ & -0.060 & -0.134 & -0.138 & 0.095 & 0.140 & -0.085 & 1 \\
\hline
\end{tabular}

Note. Each value indicates the Pearson's correlation coefficient of a pair of parameters. * and ** denote correlations that are significantly different at $p \leq 0.05$ and $p \leq 0.01$, respectively

Table 3

Pearson's correlation coefficients ( $r$ values) among physiological parameters in rice seedling exposed to salt stress $(150 \mathrm{mM} \mathrm{NaCl})$

\begin{tabular}{llllllll}
\hline Parameter & $P_{\mathrm{N}}$ & $g_{\mathrm{s}}$ & $\mathrm{E}$ & $\mathrm{WUE}$ & $F_{0}$ & $F_{\mathrm{m}}$ & $F_{\mathrm{v}} / F_{\mathrm{m}}$ \\
\hline$P_{\mathrm{N}}$ & 1 & & & & & \\
$g_{\mathrm{s}}$ & $0.576^{* *}$ & 1 & & & & \\
$\mathrm{E}$ & $0.755^{* *}$ & $0.639^{* *}$ & 1 & & & & \\
WUE & $0.828^{* *}$ & $0.436^{*}$ & $0.539^{* *}$ & 1 & & & \\
$F_{0}$ & $-0.555^{* *}$ & $-0.710^{* *}$ & $-0.623^{* *}$ & $-0.441^{*}$ & 1 & & \\
$F_{\mathrm{m}}$ & $0.585^{* *}$ & $0.473^{*}$ & $0.692^{* *}$ & $0.652^{* *}$ & $-0.642^{* *}$ & 1 & 1 \\
$F_{\mathrm{V} / F \mathrm{~m}}$ & $0.448^{*}$ & $0.677^{* *}$ & $0.532^{* *}$ & 0.386 & $-0.746^{* *}$ & $0.688^{* *}$ & 1 \\
$F_{\mathrm{v}}{ }^{\prime} / F_{\mathrm{m}}{ }^{\prime *}$ & 0.306 & $0.493^{*}$ & $0.576^{* *}$ & 0.250 & $-0.614^{* *}$ & $0.651^{* *}$ & $0.693^{* *}$ \\
$\mathrm{NPQ}$ & -0.383 & $-0.639^{* *}$ & $-0.537^{* *}$ & -0.371 & $0.714^{* *}$ & $-0.638^{* *}$ & $-0.769^{* *}$ \\
$\mathrm{SPAD}$ & $0.646^{* *}$ & $0.601^{* *}$ & $0.726^{* *}$ & $0.519^{* *}$ & $-0.687^{* *}$ & $0.852^{* *}$ & $0.659^{* *}$ \\
$\mathrm{TC}$ & $0.677^{* *}$ & $0.603^{* *}$ & $0.646^{* *}$ & $0.611^{* *}$ & $-0.568^{* *}$ & $0.627^{* *}$ & $0.689^{* *}$ \\
$\mathrm{Chl} a$ & $0.533^{* *}$ & $0.568^{* *}$ & $0.494^{*}$ & $0.463^{*}$ & $-0.492^{*}$ & $0.452^{*}$ & $0.743^{* *}$ \\
$\mathrm{Ch} l b$ & $0.627^{* *}$ & $0.416^{*}$ & $0.619^{* *}$ & $0.594^{* *}$ & $-0.457^{*}$ & $0.645^{* *}$ & 0.331 \\
$\mathrm{CA}$ & $0.443^{*}$ & 0.372 & $0.525^{* *}$ & $0.495^{* *}$ & $-0.418^{*}$ & $0.752^{* *}$ & $0.576^{* *}$ \\
\hline
\end{tabular}


Table 3 (Continued)

\begin{tabular}{|c|c|c|c|c|c|c|c|}
\hline Parameter & $F_{\mathrm{v}}{ }^{\prime} / \mathrm{F}_{\mathrm{m}}{ }^{\prime}$ & NPQ & SPAD & $\mathrm{TC}$ & Chl $a$ & $\mathrm{Chl} b$ & $\mathrm{CA}$ \\
\hline \multicolumn{8}{|l|}{$P_{\mathrm{N}}$} \\
\hline \multicolumn{8}{|l|}{$g_{\mathrm{s}}$} \\
\hline \multicolumn{8}{|l|}{$\mathrm{E}$} \\
\hline \multicolumn{8}{|l|}{ WUE } \\
\hline \multicolumn{8}{|l|}{$F_{0}$} \\
\hline \multicolumn{8}{|l|}{$F_{\mathrm{m}}$} \\
\hline \multicolumn{8}{|l|}{$F \mathrm{v} / F \mathrm{~m}$} \\
\hline$F_{\mathrm{v}}{ }^{\prime} / F_{\mathrm{m}}{ }^{\prime}$ & 1 & & & & & & \\
\hline NPQ & $-0.663^{* *}$ & 1 & & & & & \\
\hline SPAD & $0.466^{*}$ & $-0.651^{* *}$ & 1 & & & & \\
\hline $\mathrm{TC}$ & $0.467^{*}$ & $-0.635^{* *}$ & $0.596^{* *}$ & 1 & & & \\
\hline Chl $a$ & $0.478^{*}$ & $-0.619^{* *}$ & 0.401 & $0.902^{* *}$ & 1 & & \\
\hline Chl $b$ & 0.264 & $-0.406^{*}$ & $0.656^{* *}$ & $0.750^{* *}$ & 0.391 & 1 & \\
\hline $\mathrm{CA}$ & $0.593^{* *}$ & $-0.542^{* *}$ & $0.558^{* *}$ & $0.521^{* *}$ & $0.450^{*}$ & $0.421^{*}$ & 1 \\
\hline
\end{tabular}

Note. Each value indicates the Pearson's correlation coefficient of a pair of parameters. * and ** denote correlations that are significantly different at $p \leq 0.05$ and $p \leq 0.01$, respectively

\section{Cluster Analysis among Lines/Cultivars under Drought and Salt Stress}

All six rice lines/cultivar were classified into three groups as indicated by the PC-ORD program at $75 \%$ similarity based on fourteen photosynthetic traits. Under drought stress, the dendrogram divided the rice into three groups. 'KDML105' and DH103 each formed a group individually, whereas all four improved lines were clustered into one group (Figure 4A). Under salt stress, the six rice lines/cultivar were also divided into three groups: the first group included DH103 and RGD4, the second group included 'KDML105', and the third group included CSSL94, CSSL103, and RGD1 (Figure 4B).

\section{DISCUSSION}

The ability of plants to tolerate, survive, and grow in adverse environments depends directly on the efficiency of photosynthesis. The major components limiting photosynthesis under drought and salt stress include a reduction in chlorophyll content, decrease in photochemical efficiency of PSII, limitation of $\mathrm{CO}_{2}$ diffusion due to stomatal closure, and reduction in the activity of photosynthetic enzymes (Ashraf \& Harris, 2013; Pandey \& Shukla, 2015; Sudhir \& Murthy, 2004). In this study, photosynthesis-related traits, including leaf greenness, photosynthetic pigments, PSII photochemical efficiency, and 


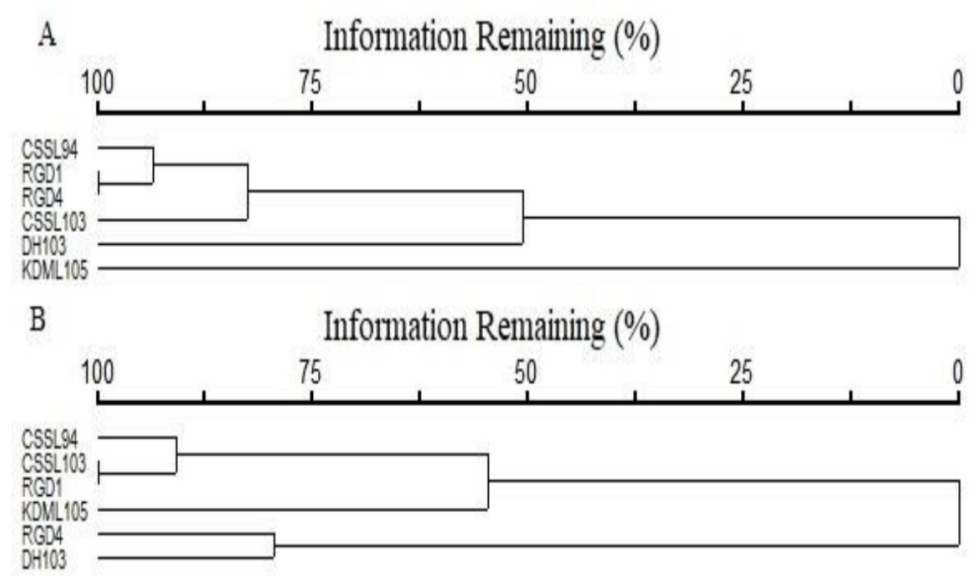

Figure 4. Dendrogram showing similarity among improved lines of rice 'KDML105' (CSSL94, CSSL103, RGD1, and RGD4), 'KDML105' and DH103 based on leaf photosynthetic parameters under (A) drought stress $(20 \%$ PEG6000) and (B) salt stress $(150 \mathrm{mM} \mathrm{NaCl})$ at the seedling stage

stomatal conductance, had strong positive correlations with the net $\mathrm{CO}_{2}$ fixation rate under stress conditions (Tables 2 and 3 ). This indicates the strong influences of pigment contents, energy transfer efficiency in the photosystem, and stomatal limitation on photosynthetic performance (Moradi \& Ismail, 2007).

The leaf greenness values (SPAD reading) and photosynthetic pigments are indicators that can be related to photosynthetic performance. As indicated in this study, $P_{\mathrm{N}}$ was highly significantly correlated with chlorophyll contents and SPAD readings (Tables 2 and 3 ). A decrease in chlorophyll content under salt stress is a commonly reported phenomenon in various studies because of the adverse effects of sodium ions on the stability of the chloroplast membrane (Ashraf \& Bhatti, 2000; Pongprayoon et al., 2019). A drought stress-induced reduction in photosynthetic pigments occurred in conjunction with damage to chloroplast structure and the photosynthetic apparatus, consequently inhibiting net $\mathrm{CO}_{2}$ assimilation (Kalefetoğlu Macar \& Ekmekçi, 2009; Li et al., 2006; Wang et al., 2018). Photosynthetic pigments and SPAD readings were used as indicators of abiotic stress tolerance, where less reduction in pigment contents or SPAD readings under stress indicated a higher level of plant stress tolerance (Jinwen et al., 2009; Munns et al., 2006). For rice, under both drought (Kumari et al., 2019) and salt stress (Lee et al., 2013), more sensitive varieties showed a greater reduction in chlorophyll content than the more tolerant varieties. In the present study, drought and salt stress decreased photosynthetic pigments and SPAD readings, and these parameters were closely related (Tables 2 and 3). Moreover, 
all improved lines of 'KDML105', which carried DT-QTLs (CSSL94 and CSSL103) or SKC1 gene (RGD1 and RGD4), had higher chlorophyll, carotenoids and SPAD readings than the sensitive parent 'KDML105' under both stress conditions. Co-expression network analysis of genes located in the DT-QTL that was introgressed into CSSL94 (Nounjan et al., 2018) revealed that the gene Os08g41990 involved in chlorophyll biosynthetic processes might play a role in maintaining chlorophyll content under salt stress.

The effects of drought and salt stress on the leaf PSII photochemical efficiency were expressed in terms of $F_{0}, F_{\mathrm{m}}, F_{\mathrm{v}} / F_{\mathrm{m}}$, $F_{\mathrm{v}}{ }^{\prime} / F_{\mathrm{m}}{ }^{\prime}$, and NPQ (Moradi \& Ismail, 2007; Li et al., 2006). It was previously reported that drought and salt stress reduced $F_{\mathrm{m}}$, $F_{\mathrm{v}} / F_{\mathrm{m}}$, and $F_{\mathrm{v}}{ }^{\prime} / F_{\mathrm{m}}{ }^{\prime}$ and increased $F_{0}$ and NPQ (Dongsansuk et al., 2013; Mishra \& Panda, 2017). A reduction in $F_{\mathrm{m}}, F_{\mathrm{v}} / F_{\mathrm{m}}$, and $F_{\mathrm{v}}{ }^{\prime} / F_{\mathrm{m}}{ }^{\prime}$ indicates that the thylakoid membrane and chloroplast are damaged due to photoinhibition leading to a decrease in $P_{\mathrm{N}}$ (Murata et al., 2007; Ranjbarfordoei et al., 2006). Similar results were found in this study, where drought and salt stress lowered the leaf PSII photochemical efficiency in rice seedlings of all lines/cultivar. Chlorophyll fluorescence analysis of 232 diverse rice genotypes clearly showed that less reduction in $F_{\mathrm{m}}, F_{\mathrm{v}} / F_{\mathrm{m}}$, and $F_{\mathrm{v}}{ }^{\prime} / F_{\mathrm{m}}{ }^{\prime}$ and less increase in $F_{0}$ and NPQ were associated with higher salt tolerance ability (Tsai et al., 2019). Under both drought and salt stress, all improved lines had significantly higher $\mathrm{F}_{\mathrm{v}}{ }^{\prime} / F_{\mathrm{m}}$ ' than 'KDML105'. A reduction in
PSII photochemical efficiency was reported to be highly correlated with a reduction in net photosynthesis rate under drought (Iqbal et al., 2019), which is like the results in this study (Table 2 ). In contrast, $F_{0}$ and NPQ increased when plants were subjected to drought and salt treatments. An increase in $F_{0}$ was associated with photoinactivation and damage to PSII reaction centers, while NPQ indicated the photoprotective processes that removed excess excitation energy to prevent the formation of harmful free radicals (Murchie \& Lawson, 2013). All improved lines (CSSL94, CSSL103, RGD1, and RGD4) showed higher $F_{\mathrm{v}}{ }^{\prime} / F_{\mathrm{m}}{ }^{\prime}$ and lower NPQ than the parental line 'KDML105', indicating more efficient use of light energy in photochemical reaction and therefore less non-photochemical energy dissipation. Similar findings by Dongsansuk et al. (2013) reported that salt stress also caused a dramatic reduction in $F_{\mathrm{v}}{ }^{\prime} / F_{\mathrm{m}}{ }^{\prime}$, while NPQ was increased in 'KDML105'. In contrast, leaf PSII photochemical efficiency was unaffected by salt stress in Pokkali (salttolerant variety). Mishra and Panda (2017) also reported that the tolerant variety N22 showed higher $F_{\mathrm{m}}$ and $F_{\mathrm{v}} / F_{\mathrm{m}}$ as well as lower $F_{0}$ and NPQ under drought stress than the susceptible variety IR64. In comparison with 'KDML105', all improved lines in this study also showed higher $F_{\mathrm{m}}$ and $F_{\mathrm{v}} / F_{\mathrm{m}}$ as well as lower $F_{0}$ and NPQ under drought and salt stress.

A decline in photochemical efficiency under drought and salt stress which leads to reduced light-dependent NADPH and ATP synthesis, combined with a reduction in $\mathrm{CO}_{2}$ 
uptake and diffusion due to stomatal closure, results in lower $\mathrm{CO}_{2}$ fixation and Calvin cycle activities (Chaves et al., 2009). Hence, the $P_{\mathrm{N}}$ of rice in this study was dramatically reduced from an average (across genotypes) of $23.08 \mu \mathrm{mol}\left(\mathrm{CO}_{2}\right) \mathrm{m}^{-2} \mathrm{~s}^{-1}$ in the controls to $4.86 \mu \mathrm{mol}\left(\mathrm{CO}_{2}\right) \mathrm{m}^{-2} \mathrm{~s}^{-1}$ under drought and $9.87 \mu \mathrm{mol}\left(\mathrm{CO}_{2}\right) \mathrm{m}^{-2} \mathrm{~s}^{-1}$ under salt stress (Figure 1A; Tables 2 and 3). Based on the observation of Ramegowda et al. (2014), a similar level of reduction in $P_{\mathrm{N}}$ of rice at the vegetative growth stage was demonstrated, dropping from $21 \mu \mathrm{mol}\left(\mathrm{CO}_{2}\right) \mathrm{m}^{-2} \mathrm{~s}^{-1}$ under control conditions to approximately $6 \mu \mathrm{mol}$ $\left(\mathrm{CO}_{2}\right) \mathrm{m}^{-2} \mathrm{~s}^{-1}$ under drought stress. For salt stress, Nounjan et al. (2018) found that the $P_{\mathrm{N}}$ of 'KDML105' declined from $24 \mu \mathrm{mol}$ $\left(\mathrm{CO}_{2}\right) \mathrm{m}^{-2} \mathrm{~s}^{-1}$ to $4 \mu \mathrm{mol}\left(\mathrm{CO}_{2}\right) \mathrm{m}^{-2} \mathrm{~s}^{-1}$ when subjected to salt stress at $16.50 \mathrm{dS} \mathrm{m}^{-1}$ for 9 days. Under slightly lower stress levels in this study (14.8 dS m-1 for 10 days), $P_{\mathrm{N}}$ of 'KDML105' decreased from 23.45 to 7.90 $\mu \mathrm{mol}\left(\mathrm{CO}_{2}\right) \mathrm{m}^{-2} \mathrm{~s}^{-1}$ (Figure 1A).

Simultaneous investigations on the effects of drought and salt stress on rice have rarely been reported, and this study demonstrated that drought imposed a stronger inhibitory effect than salt stress on photosynthesis in rice. Although the PEG and $\mathrm{NaCl}$ solutions had an equal osmotic potential of $-0.7 \mathrm{MPa}$ and were expected to induce similar levels of osmotic stress, a greater reduction in pigment contents and most photosynthetic parameters was recorded in the drought-induced PEG solutions (Figures 1A and 1B). This could be due to some intrinsic limitations of using PEG to simulate drought conditions, such as the viscosity of the solution and absorption of PEG by roots, thus resulting in less water uptake, root damage, and leaf dysfunction (Osmolovskaya et al., 2018). Moreover, PEG solutions caused more rapid leaf rolling, compared to $\mathrm{NaCl}$ solution, leading to lower leaf surface area exposed to sunlight, hence lower photosynthesis rate. On the other hand, the negative effects of salt stress on photosynthesis were due to osmotic stress, which mainly induced stomatal closure as well as ion toxicity stress, which occurs as a result of excess $\mathrm{Na}^{+}$ accumulation in the chloroplasts (Munns \& Tester, 2008). The direct influences of excess $\mathrm{Na}^{+}$on photosynthesis were associated with the disruption of the proton motive force necessary for ATP production as well as its interference with $\mathrm{CO}_{2}$ fixing enzymes (van Zelm et al., 2020).

In this study, all improved lines of 'KDML105', namely CSSL94, CSSL103, RGD1, and RGD4, showed greater values in $P_{\mathrm{N}}$ and all related gas exchange parameters ( $g_{\mathrm{s}}, E$, and WUE) than the parental cultivar 'KDML105' under both drought and salt stress. In the case of CSSL94, similar results were demonstrated by Nounjan et al. (2016), where CSSL94 had higher $P_{\mathrm{N}}$ under salinity stress compared to 'KDML105'. Co-expression network analysis of genes located in the DT-QTL introgressed into CSSL94 (Nounjan et al., 2018) revealed that the gene Os08g41990 involved in chlorophyll biosynthetic process might play a role in maintaining chlorophyll content under salt stress. Consequently, this may lead to the higher photosynthetic 
performance of CSSL94. However, photosynthesis of this line under drought stress has not been observed. In a study using a related near-isogenic line from the same CSSL population, Chutimanukul et al. (2018) reported that rice line CSSL16 (improved 'KDML105' introgressed with DT-QTL segments from chromosome 1 of DH212) showed a much lower reduction in photosynthesis under salt stress than 'KDML105'. From the co-expression analysis study, ten hub genes on the DTQTL were found, of which six functioned in chloroplasts. One of these genes, PsbSI, which encodes the CP22 protein located in PSII, was proven to play a protective role through its activity in non-photochemical quenching under salt stress (Chutimanukul et al., 2018). The $S K C 1$ gene, also known as $O s H K T 1 ; 5$ in rice, is responsible for the regulation of $\mathrm{Na}^{+}$in the shoot and is more highly expressed in rice genotypes with higher salt tolerance associated with good maintenance of various physiological status, including higher photosynthetic capacity (Ueda et al., 2013). Transfer of the HKT1;5 genes from maize into tobacco resulted in transgenic tobacco with enhanced salt tolerance (Jiang et al., 2018). The crucial role of this gene in enhancing salt tolerance was confirmed in the present study. The introgression lines (RGD1 and RGD4) carrying this gene, which was transferred from a salt-tolerant donor into the genetic background of 'KDML105', showed higher salt tolerance, as indicated by a significantly higher $P_{\mathrm{N}}$ and other related gas exchange parameters of these lines compared to 'KDML105' under salt treatments (Figure 1). Moreover, the photosynthetic performance of these lines under drought stress was also superior to 'KDML105'. This is the first report on physiological studies, particularly in relation to photosynthesis, of these lines under salt and drought stress.

The results in this study clearly showed that introgression of DT-QTLs into the drought-sensitive 'KDML105' not only conferred drought tolerance ability to the improved lines (CSSL94 and CSSL103) but also enhanced salt resistance. Similar work by Basu et al. (2017) revealed two drought-tolerant breeding lines with superior drought and salinity tolerance based on several physiological parameters, including photosynthesis. Moreover, introgression lines (RGD1 and RGD4) of 'KDML105' carrying $S K C 1$ gene were more tolerant not only to salt stress but also to drought stress, as indicated by enhanced photosynthetic performance. As suggested by Nounjan et al. (2016), photosynthesis is an important target trait for the selection of breeding lines tolerant to drought and salt stress, and improving crop yield relies largely on photosynthetic performance (Zhu et al., 2010). Thus, these improved lines with high photosynthetic capacity are potentially useful as genetic resources for developing improved Thai jasmine rice lines for multiple stress tolerance via gene pyramiding. 


\section{CONCLUSION}

Thai jasmine rice 'KDML105' is sensitive to drought and salinity. This study highlighted a search for improved rice breeding lines with a 'KDML105' genetic background that better tolerate drought and salinity stress based on photosynthesis-related characters, including better maintenance of pigments, PSII photochemical efficiency, and net photosynthesis rate. The improved photosynthetic performance under drought and salt stress of CSSL94, CSSL103, RGD1, and RGD4 indicated that these lines have the potential to be used in the rice breeding program and targeted for improvement of multiple stress tolerance.

\section{ACKNOWLEDGEMENTS}

This work was financially supported by the Agricultural Research Development Agency, National Research Council of Thailand, and Science Achievement Scholarship of Thailand (SAST). The authors wish to thank the Faculty of Agriculture for providing greenhouse space.

\section{REFERENCES}

Ambavaram, M. M., Basu, S., Krishnan, A., Ramegowda, V., Batlang, U., Rahman, L., ... Pereira, A. (2014). Coordinated regulation of photosynthesis in rice increases yield and tolerance to environmental stress. Nature Communications, 5(1), 1-14. doi: 10.1038/ ncomms6302

Anami, B. S., Malvade, N. N., \& Palaiah, S. (2020). Classification of yield affecting biotic and abiotic paddy crop stresses using field images.
Information Processing in Agriculture, 7(2), 272-285. doi: 10.1016/j.inpa.2019.08.005

Arnon, D. I. (1949). Copper enzymes in isolated chloroplasts polyphenoloxidase in Beta vulgaris. Plant Physiology, 24(1), 1-15. doi: 10.1104/ pp.24.1.1

Arunin, S., \& Pongwichian, P. (2015). Salt-affected soils and management in Thailand. Bulletin of the Society of Sea Water Science, Japan, 69(5), 319-325. doi: 10.11457/swsj.69.319

Ashraf, M. Y., \& Bhatti, A. S. (2000). Effect of salinity on growth and chlorophyll content in rice. Pakistan Journal of Scientific and Industrial Research, 43(2), 130-131.

Ashraf, M., \& Harris, P. J. C. (2013). Photosynthesis under stressful environments: An overview. Photosynthetica, 51(2), 163-190. doi: 10.1007/ s11099-013-0021-6

Basu, S., Giri, R. K., Benazir, I., Kumar, S. Rajwanshi, R., Dwivedi, S. K., \& Kumar, G. (2017). Comprehensive physiological analyses and reactive oxygen species profiling in drought tolerant rice genotypes under salinity stress. Physiology and Molecular Biology of Plants, 23(4), 837-850. doi: 10.1007/s12298-0170477-0

Bilger, W., \& Björkman, O. (1990). Role of the xanthophylls cycle in photoprotection elucidated by measurements of light-induced absorbance changes, fluorescence and photosynthesis in Hedera canariensis. Photosynthesis Research, 25(3), 173-185. doi: 10.1007/bf00033159

Chaves, M. M., Flexas, J., \& Pinheiro, C. (2009). Photosynthesis under drought and salt stress: Regulation mechanisms from whole plant to cell. Annals of Botany, 103(4), 551-560. doi: 10.1093/aob/men125 
Chutimanukul, P., Kositsup, B., Plaimas, K., Buaboocha, T., Siangliw, M., Toojinda, T., ... Chadchawan, S. (2018). Photosynthetic responses and identification of salt tolerance genes in a chromosome segment substitution line of 'Khao Dawk Mali 105' rice. Environmental and Experimental Botany, 155, 497-508. doi: 10.1016/j.envexpbot.2018.07.019

Clermont-Dauphin, C., Suwannang, N., Grünberger, O., Hammecker, C., \& Maeght, J. L. (2010). Yield of rice under water and soil salinity risks in farmers' fields in northeast Thailand. Field Crops Research, 118(3), 289-296. doi: 10.1016/j. fcr.2010.06.009

Dongsansuk, A., Lontom, W., Wannapat, S., \& Theerakulpisut, P. (2013). The performance of PSII efficiency and growth response to salt stress in three rice varieties differing in salt tolerance. Agricultural Science Journal, 44(2), 639-648.

Gregorio, G. B., Senadhira, D., Mendoza, R. D., Manigbas, N. L., Roxas, J. P., \& Guerta, C. Q. (2002). Progress in breeding for salinity tolerance and associated abiotic stresses in rice. Field Crops Research, 76(2-3), 91-101. doi: 10.1016/s0378-4290(02)00031-x

Gururani, M. A., Venkatesh, J., \& Tran, L. S. P. (2015). Regulation of photosynthesis during abiotic stress-induced photoinhibition. Molecular Plant, 8(9), 1304-1320. doi: 10.1016/j. molp.2015.05.005

Hungsaprug, K., Utkhao, W., Kositsup, B., Kasettranun, W., Siangliw, J. L., Toojinda, T., \& Chadchawan, S. (2019). Photosynthetic parameters and biomass recovery of a rice chromosome segment substitution line with a 'KDML 105' genetic background under drought conditions. International Journal of Agriculture and Biology, 22(5), 1197-1204. doi: 10.17957/ $\mathrm{IJAB} / 15.1187$
Iqbal, N., Hussain, S., Raza, M. A., Yang, C., Safdar, M. E., Brestic, M., ... Liu, J. (2019). Drought tolerance of soybean (Glycine max L. Merr.) by improved photosynthetic characteristics and an efficient antioxidant enzyme system under a split-root system. Frontiers in Physiology, 10, 786. doi: 10.3389/fphys.2019.00786

Jiang, Z., Song, G., Shan, X., Wei, Z., Liu, Y., Jiang, C., ... Li, Y. (2018). Association analysis and identification of ZmHKT1; 5 variation with saltstress tolerance. Frontiers in Plant Science, 9, 1485. doi: 10.3389/fpls.2018.01485

Jinwen, L., Jingping, Y., Pinpin, F., Junlan, S., Dongsheng, L., Changshui, G., \& Wenyue, C. (2009). Responses of rice leaf thickness, SPAD readings and chlorophyll $a / b$ ratios to different nitrogen supply rates in paddy field. Field Crops Research, 114(3), 426-432. doi: 10.1016/j. fcr.2009.09.009

Jongdee, B., Pantuwan, G., Fukai, S., \& Fischer, K. (2006). Improving drought tolerance in rainfed lowland rice: An example from Thailand. Agricultural Water Management, 80(1-3), 225-240. doi: 10.1016/j.agwat.2005.07.015

Kalefetoğlu Macar, T., \& Ekmekçi, Y. (2009). Alterations in photochemical and physiological activities of chickpea (Cicer arietinum L.) cultivars under drought stress. Journal of Agronomy and Crop Science, 195(5), 335-346. doi: 10.1111/j.1439-037x.2009.00374.x

Kanawapee, N., Sanitchon, J., Lontom, W., \& Theerakulpisut, P. (2012). Evaluation of salt tolerance at the seedling stage in rice genotypes by growth performance, ion accumulation, proline and chlorophyll content. Plant and Soil, 358(1-2), 235-349. doi: 10.1007/s11104-012$1179-6$

Kanjoo, V. (2011). Development of chromosome segment substitution lines related to drought 
tolerance in rice (Oryza sativa L.) (Doctoral's thesis), Kasetsart University, Thailand.

Kanjoo, V., Punyawaew, K., Siangliw, J. L., Jearakongman, S., Vanavichit, A., \& Toojinda, T. (2012). Evaluation of agronomic traits in chromosome segment substitution lines of KDML105 containing drought tolerance QTL under drought stress. Rice Science, 19(2), 117-124. doi: 10.1016/s1672-6308(12)60030-4

Kumari, R., Choudhury, D., Goswami, S., \& Dey, N. (2019). Physiological, biochemical, and molecular screening of selected upland rice (Oryza sativa L.) lines from eastern India. Bulletin of the National Research Centre, 43(1), 56. doi: 10.1186/s42269-019-0087-9

Lanceras, J. C., Pantuwan, G., Jongdee, B., \& Toojinda, T, (2004). Quantitative trait loci associated with drought tolerance at reproductive stage in rice. Plant Physiology, 135(1), 384-399. doi: $10.1104 /$ pp.103.035527

Lee, M. H., Cho, E. J., Wi, S. G., Bae, H., Kim, J. E. Cho, J., ... Chung, B. Y. (2013). Divergences in morphological changes and antioxidant responses in salt-tolerant and salt-sensitive rice seedlings after salt stress. Plant Physiology and Biochemistry, 70, 325-335. doi: 10.1016/j. plaphy.2013.05.047

Li, Q., Yang, A., \& Zhang, W. (2017). Comparative studies on tolerance of rice genotypes differing in their tolerance to moderate salt stress. $B M C$ Plant Biology, 17(1), 1-13. doi: 10.1186/s12870017-1089-0

Li, R. H., Guo, P. G., Michael, B., Stefania, G., \& Salvatore, C. (2006). Evaluation of chlorophyll content and fluorescence parameters as indicators of drought tolerance in barley. Agricultural Sciences in China, 5(10), 751-757. doi: 10.1016/ s1671-2927(06)60120-x
Lichtenthaler, H. K. (1987). Chlorophylls and carotenoids, pigments of photosynthetic biomembranes. Methods in Enzymology, 148, 350-382. doi: 10.1016/0076-6879(87)48036-1

Lin, W., Guo, X., Pan, X., \& Li, Z. (2018). Chlorophyll composition, chlorophyll fluorescence, and grain yield change in esl mutant rice. Retrieved January 24, 2020, from https://www.ncbi.nlm. nih.gov/pmc/articles/PMC6213484/pdf/ijms19-02945.pdf

Mishra, S. S., \& Panda, D. (2017). Leaf traits and antioxidant defense for drought tolerance during early growth stage in some popular traditional rice landraces from Koraput, India. Rice Science, 24(4), 207-217. doi: 10.1016/j.rsci.2017.04.001

Moradi, F., \& Ismail, A. M. (2007). Responses of photosynthesis, chlorophyll fluorescence and ROS-scavenging systems to salt stress during seedling and reproductive stages in rice. Annals of Botany, 99(6), 1161-1173. doi: 10.1093/aob/ $\mathrm{mcm} 052$

Munns, R., \& Tester, M. (2008). Mechanisms of salinity tolerance. Annual Review of Plant Biology, 59, 651-681. doi: 10.1146/annurev. arplant.59.032607.092911

Munns, R., James, R. A., \& Lauchli, A. (2006). Approaches to increasing the salt tolerance of wheat and other cereals. Journal of Experimental Botany, 57(5), 1025-1043. doi: 10.1093/jxb/ erj100

Murata, N., Takahashi, S., Nishiyama, S., Nishiyama, Y., \& Allakhverdiev, S. I. (2007). Photoinhibition of photosystem II under environmental stress. Biochimica et Biophysica ActaBioenergetics, 1767(6), 414-421. doi: 10.1016/j. bbabio.2006.11.019

Murata, Y. (1981). Dependence of the potential productivity and efficiency in solar energy 
utilization on leaf photosynthetic capacity in crop species. Japanese Journal of Crop Science, 50(2), 223-232. doi: 10.1626/jcs.50.223

Murchie, E. H., \& Lawson, T. (2013). Chlorophyll fluorescence analysis: A guide to good practice and understanding some new applications. Journal of Experimental Botany, 64(13), 39833998. doi:10.1093/jxb/ert208

Netondo, G. W., Onyango, J. C., \& Beck, E. (2004). Sorghum and salinity: II. Gas exchange and chlorophyll fluorescence of sorghum under salt stress. Crop Science, 44(3), 806-811. doi: $10.2135 /$ cropsci2004.8060

Nishiyama, Y., Allakhverdiev, S. I., \& Murata, N. (2006). A new paradigm for the action of reactive oxygen species in the photoinhibition of photosystem II. Biochimica et Biophysica ActaBioenergetics, 1757(7), 742-749. doi: 10.1016/j. bbabio.2006.05.013

Nounjan, N., Chansongkrow, P., Charoensawan, V., Lanceras-Siangliw, J., Toojinda, T., Chadchawan, S., \& Theerakulpisut, P. (2018). High performance of photosynthesis and osmotic adjustment are associated with salt tolerance ability in rice carrying drought tolerance QTL: Physiological and co-expression network analysis. Frontiers Plant Science, 9, 1135. doi: 10.3389/fpls.2018.01135

Nounjan, N., Siangliw, J. L., Toojinda, T., Chadchawan, S., \& Theerakulpisut, P. (2016). Salt-responsive mechanisms in chromosome segment substitution lines of rice (Oryza sativa L. cv. KDML105). Plant Physiology and Biochemistry, 103, 96-105. doi: 10.1016/j. plaphy.2016.02.038

Osmolovskaya, N., Shumilina, J., Kim, S., Didio, A., Grishina, T., Bilova, T., ...Wessjohann, L. A. (2018). Methodology of drought stress research: Experimental setup and physiological characterization. International Journal of Molecular Sciences, 19(12), 4089. doi: 10.3390/ ijms 19124089

Pandey, V., \& Shukla, A. (2015). Acclimation and tolerance strategies of rice under drought stress. Rice Science, 22(4), 147-161. doi: 10.1016/j. rsci.2015.04.001

Polthanee, A., Promkhumbut, A., \& Bumrungrai, J. (2014). Drought impact on rice production and farmer's adaptation strategies in Northeast Thailand. International Journal of Environmental and Rural Development, 5(1), 45-52.

Pongprayoon, W., Tisarum, R., Teerawittaya, C., \& Cha-um, S. (2019). Evaluation and clustering on salt-tolerant ability in rice genotypes (Oryza sativa L. subsp. indica) using multivariate physiological indices. Physiology and Molecular Biology of Plants, 25(2), 473-483. doi: 10.1007/ s12298-018-00636-2

Punyawaew, K., Suriya-Arunroj, D., Siangliw, M., Thida, M., Lanceras-Siangliw, J., Fukai, S., \& Toojinda, T. (2016). Thai jasmine rice cultivar KDML105 carrying Saltol QTL exhibiting salinity tolerance at seedling stage. Molecular Breeding, 36(11), 150. doi: 10.1007/s11032016-0574-8

Ramegowda, V., Basu, S., Krishnan, A., \& Pereira, A. (2014). Rice GROWTH UNDER DROUGHT KINASE is required for drought tolerance and grain yield under normal and drought stress conditions. Plant Physiology, 166(3), 16341645. doi: 10.1104/pp.114.248203

Ran, Y., Chen, H., Ruan, D., Liu, H., Wang, S., Tang, X., \& Wu, W. (2018). Identification of factors affecting rice yield gap in southwest China: An experimental study. Retrieved January 24, 2020, from https://journals.plos. org/plosone/article/file?id=10.1371/journal. pone. $0206479 \&$ type $=$ printable 
Ranjbarfordoei, A., Samson, R., \& Vandamme, P. (2006). Chlorophyll fluorescence performance of sweet almond [Prunus dulcis (Miller) D. Webb] in response to salinity stress induced by $\mathrm{NaCl}$. Photosynthetica, 44(4), 513-522. doi: 10.1007/ s11099-006-0064-Z

Ren, Z. H., Gao, J. P., Li, L. G., Cai, X. L., Huang, W., Chao, D. Y., ... Lin, H. X. (2005). A rice quantitative trait locus for salt tolerance encodes a sodium transporter. Nature Genetics, 37(10), 1141-1146. doi: 10.1038/ng1643

Rötzer, T., Seifert, T., Gayler, S., Priesack, E., \& Pretzsach, H. (2012). Effects of stress and defense allocation on tree growth: Simulation results at the individual and stand level. In R. Matyssek, H. Schnyder, W. Oßwald, D. Ernst, J. C. Munch, \& H. Pretzsch (Eds.), Growth and defense in plants (pp. 401-432). Berlin, Germany: Springer Nature. doi: 10.1007/978-3642-30645-7_18

Schreiber, U. (2004). Pulse-amplitude-modulation (PAM) fluorometry and saturation pulse method: An overview. In T. D. Sharkey (Ed.), Advances in photosynthesis and respiration (pp. 279319). Berlin, Germany: Springer Nature. doi: 10.1007/978-1-4020-3218-9_11

Sekar, I., \& Pal, S. (2012). Rice and wheat crop productivity in the Indo-Gangetic Plains of India: Changing pattern of growth and future strategies. Indian Journal of Agricultural Economics, 67(2), 238-252. doi: 10.22004/ag.econ.204809

Sudhir, P., \& Murthy, S. D. S. (2004). Effects of salt stress on basic processes of photosynthesis. Photosynthetica, 42(2), 481-486. doi: 10.1007/ s11099-005-0001-6

Thomson., M. J., Ocampo. M., Egdane, J., Rahman, M. A., Sajise, A. G., Adorada, D. L., ... Ismail, A. M. (2010). Characterizing the Saltol quantitative trait locus for salinity tolerance in rice. Rice, 3(23), 148-160. doi: 10.1007/s12284-010-9053-8
Tsai, Y. C., Chen, K. C., Cheng, T. S., Lee, C., Lin, S. H., \& Tung, C. W. (2019). Chlorophyll fluorescence analysis in diverse rice varieties revealed the positive correlation between the seedlings salt tolerance and photosynthetic efficiency. BMC Plant Biology, 19(1), 403. doi: 10.1186/s12870-019-1983-8

Ueda, A., Yahagi, H., Fujikawa, Y., Nagaoka, T., Esaka, M., Calcaño, M., ... Saneoka, H. (2013). Comparative physiological analysis of salinity tolerance in rice. Soil Science and Plant Nutrition, 59(6), 896-903. doi: 10.1080/00380768.2013.842883

van Zelm, E., Zhang, Y., \& Testerink, C. (2020). Salt tolerance mechanisms of plants. Annual Review of Plant Biology, 71, 403-433. doi: 10.1146/ annurev-arplant-050718-100005

Vanavichit, A., Kamolsukyeunyong, W., Siangliw, M., Siangliw, J. L., Traprab, S., Ruengphayak, S., ... Tragoonrung, S. (2018). Thai Hom Mali rice: Origin and breeding for subsistence rainfed lowland rice system. Rice, 11(1), 20. doi: 10.1186/s12284-018-0212-7

Wang, Z., Li, G., Sun, H., Ma, L., Guo, Y., Zhao, Z., ... Mei, L. (2018). Effects of drought stress on photosynthesis and photosynthetic electron transport chain in young apple tree leaves. Retrieved January 03, 2020, from https:/www. ncbi.nlm.nih.gov/pmc/articles/PMC6262865/ pdf/biolopen-7-035279.pdf

Yoshida, S., Fomo. D. A., Cock, J. H., \& Gomez, K. A. (1976). Laboratory manual for physiological studies of rice. Los Baños, Philippines: International Rice Research Institute.

Zhu, X., Long, S. P., \& Ort, D. R. (2010). Improving photosynthetic efficiency for greater yield. Annual Review of Plant Biology, 61, 235-261. doi: 10.1146/annurev-arplant-042809-112206 
